\title{
Combined surgery and radiotherapy as curative treatment for tracheal adenoid cystic carcinoma: a case report
}

\author{
Gian Paolo Spinelli ${ }^{*}$, Evelina Miele², Alessandra Anna Prete' ${ }^{1}$ Giuseppe Lo Russo ${ }^{1}$, Alessandro Di Marzo ${ }^{3}$, \\ Claudio Di Cristofano ${ }^{4}$ and Silverio Tomao ${ }^{1}$
}

\begin{abstract}
Background: Adenoid cystic carcinoma of the trachea is a rare tumor, characterized by slow growth and low rate of local and distant metastasis. When achievable, complete surgical resection represents the optimal treatment approach, with the highest results in terms of overall survival. Radiation therapy is a reasonable alternative in cases of inoperable disease.

Case presentation: We report a case of an 82-year-old white man affected by primary adenoid cystic carcinoma of the trachea, treated with debulking surgery and radiotherapy on the residual disease.

A three-dimensional conformal radiation therapy was conducted. The total dose amounted to $70 \mathrm{~Gy}$, administered in 35 fractions of $2 \mathrm{~Gy}$. The medium doses given to the esophagus and lungs were $23 \mathrm{~Gy}$ and $4.2 \mathrm{~Gy}$ respectively. The maximum dose delivered to the spinal cord was $31 \mathrm{~Gy}$ with satisfactory results in terms of local control of the disease.

Conclusion: A combined approach of surgical resection followed by radiotherapy on the residual disease provided an excellent result in terms of disease control, quality of life, and overall survival in a patient with locally advanced tracheal adenoid cystic carcinoma.
\end{abstract}

Keywords: Adenoid cystic carcinoma (ACC), Trachea, Radiotherapy, Surgery

\section{Background}

Primary tracheal malignant tumors represent 0.1 to $0.4 \%$ of all malignant neoplastic diseases and their incidence is approximately 0.1 per 100,000 per year. Malignant tumors of the trachea tend to occur more often in the adult population than in children, but the distribution between the two sexes is almost the same.

Primary adenoid cystic carcinoma (ACC) of the trachea and squamous cell carcinoma (SCC) are the most frequent histological types of tracheal malignant tumors, accounting for approximately two thirds of adult primary tracheal tumors. The other histological classes are very rare and include sarcoma, melanoma, mucoepidermoid carcinoma, lymphoma, and non-squamous bronchogenic carcinoma.

\footnotetext{
* Correspondence: gianpaolo.spinelli@uniroma1.it

'UOC of Oncology - ASL Latina - Distretto 1, University of Rome "Sapienza", Aprilia, LT, Italy

Full list of author information is available at the end of the article
}

ACC seems not to be related to tobacco smoking, and its prognosis is generally better than SCC, which progresses faster and frequently metastasizes. In contrast, only $10 \%$ of patients affected by ACC present with locoregional or distant metastases. The main growth patterns of tracheal ACC documented in histological samples are tubular, solid, and cribriform, the latter is the most frequently observed.

Local recurrences are not uncommon in ACC, but they are frequently late. Radical surgery is related to the best outcomes in overall survival; in unresectable tumors, radiotherapy ensures satisfactory results in terms of local control of the disease, and is adequate to treat residual disease after surgery $[1,2]$.

Here we report a case of such rare pathology that we managed it with a combinatorial strategy of surgery and radiotherapy which allowed adequate disease control.

C The Author(s). 2019 Open Access This article is distributed under the terms of the Creative Commons Attribution 4.0 International License (http://creativecommons.org/licenses/by/4.0/), which permits unrestricted use, distribution, and 


\section{Case presentation}

We report a case of an 82-year-old white man, who never smoked tobacco or consumed alcohol, who presented with a 3-month history of tracheitis and dysphonia. His past medical history was characterized by multiple myeloma, Gilbert syndrome, chronic obstructive pulmonary disease (COPD) treated with bronchodilators, cardiac arrhythmia treated with amiodarone, and arterial hypertension treated with angiotensin-converting enzyme (ACE) inhibitors.

On arrival, his physical signs were as follows: oriented, collaborating, and autonomous walking; a neurological examination showed no abnormalities; blood pressure 130/ $85 \mathrm{mmHg}$ and pulse 80 beats/minute; no fever; and regular bowel function and diuresis. Routine laboratory tests were performed, including complete blood count, renal and liver function tests, and electrolytes. All the results of the laboratory tests were almost within normal range.

A frontal and lateral chest radiograph was performed as first imaging procedure: it showed prominent pulmonary hila and a reduction of vascular marking, but no nodular lesions or neoformations were documented. Therefore he underwent a total body computed tomography (CT) scan without contrast, due to the multiple myeloma, which revealed the presence of massive hyperdense solid tissue in the mid-proximal trachea, protruding into the lumen. This neoformation determined compression and narrowing at the level of the anterior-lateral wall of the right portion of his esophagus.

Thus, he underwent a bronchoscopy that confirmed tracheal lumen narrowing between the first and fifth tracheal ring. A biopsy specimen of the lesion revealed a salivary gland-type neoplasm, showing a moderate degree of aggressiveness, with the characteristics of ACC (Fig. 1a, b).

Due to the rarity of the neoplasm, with less than two cases in 1 year in our institute, a review of the literature was made. A multidisciplinary team of oncologists, radiologists, radiotherapists, and surgeons decided to treat our patient with an endotracheal debulking surgical excision of the lesion followed by radiotherapy.

Three weeks after the surgery, a positron emission tomography (PET)/CT scan was performed: a residual solid tissue with a maximum diameter of $46 \mathrm{~mm}$ was evident in the middle mediastinum, infiltrating the upper middle third of his trachea and showing strong ${ }^{18} \mathrm{~F}$-fluorodeoxyglucose (18-FDG) uptake (Fig. 2a). A three-dimensional conformal radiation therapy (3D-CRT) was conducted. The target volume was determined by CT. Lungs, heart, left coronary artery, and spinal cord were identified as organs at risk of accidental irradiation. The radiotherapy was delivered with linear accelerator of photons. The total dose amounted to $70 \mathrm{~Gy}$, administered in 35 fractions of 2 Gy. The medium doses given to his esophagus and lungs
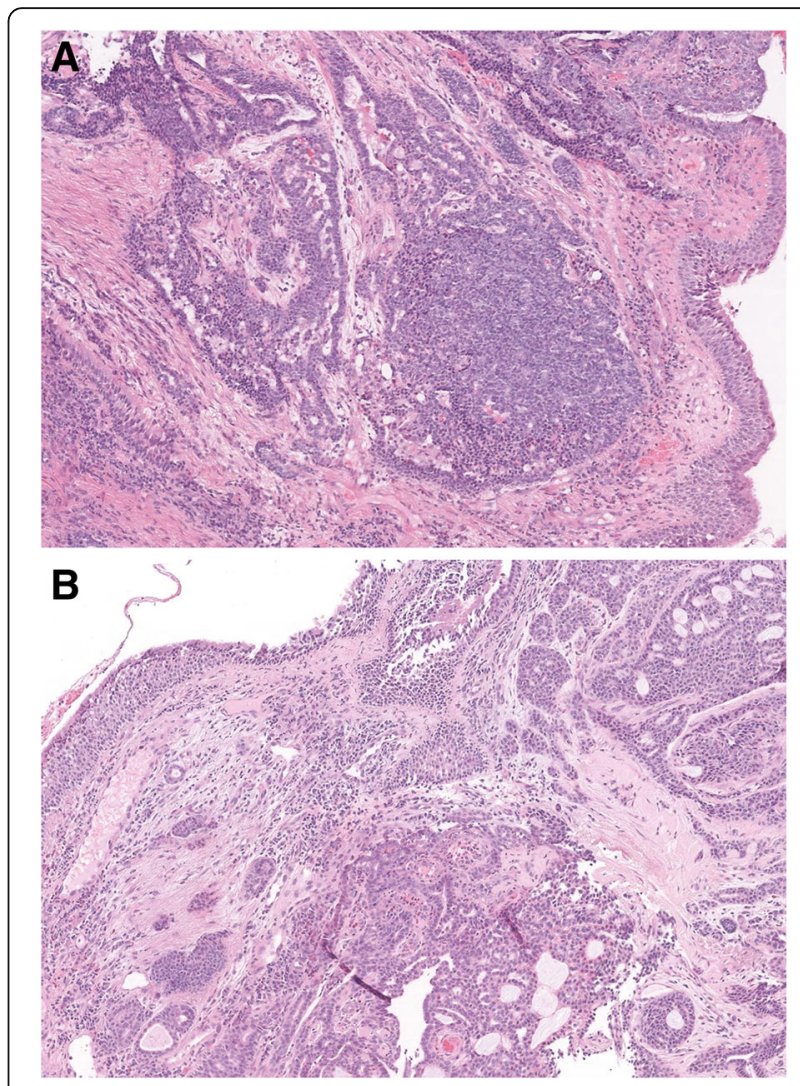

Fig. 1 a, b Neoplastic proliferation composed of small cells with basophilic nucleus, inconspicuous nucleolus and scant cytoplasm arranged in nodules with cribriform pattern, cords, and tubules of varying size, containing eosinophilic material

were $23 \mathrm{~Gy}$ and $4.2 \mathrm{~Gy}$ respectively. The maximum dose delivered to his spinal cord was $31 \mathrm{~Gy}$.

After 1 year of follow-up, no early or late toxicities related to the radiotherapy were observed: there was no dysphagia or weight loss.

PET-CT scans performed after 6 and 12 months of follow-up showed a complete response to the radiotherapy, with only a focal increased uptake at the level of superior pulmonary lobes, which referred to post-radiotherapy inflammation (Fig. 2b).

\section{Discussion}

ACC of the trachea is characterized by slow growth and low rate of local and distant metastasis.

We report the case of a patient with the rare condition of tracheal ACC that was successfully treated with a combination of surgery and radiotherapy.

$\mathrm{CT}$ and magnetic resonance proved to be the most appropriate imaging techniques for the characterization of the primary tumor and to document lymph nodal or distant metastases. A PET-CT scan is also useful for staging and has been used to direct intensity-modulated radiation therapy (IMRT) treatment. 

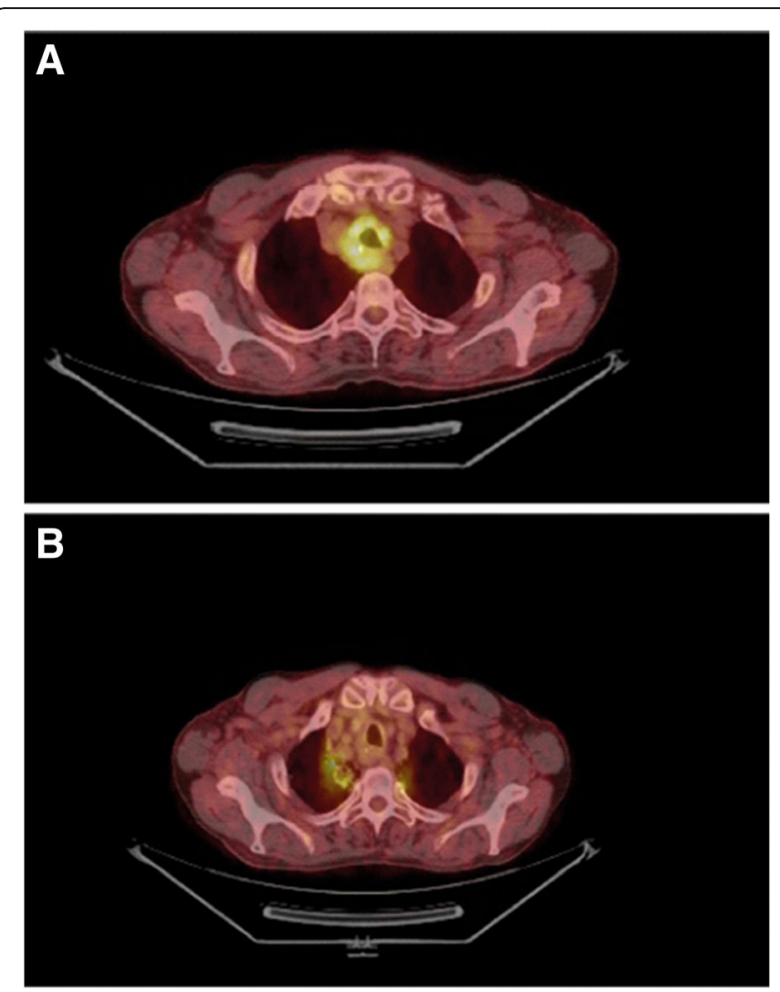

Fig. 2 a, b Positron emission tomography-computed tomography before (a) and after (b) radiotherapy. The increased uptake of ${ }^{18} \mathrm{~F}$-fluorodeoxyglucose at the level of trachea is not visible after the treatment. The increased uptake of ${ }^{18} \mathrm{~F}$-fluorodeoxyglucose in correspondence with the superior pulmonary lobes refer to the local inflammation caused by radiotherapy

A better prognosis is mainly related to the feasibility of complete resection and to the absence of metastasis. However, symptoms such as wheezing, tracheitis, hemoptysis, and stridency are often unspecific and late. Lymph nodal involvement has not been associated with a worse prognosis $[3,4]$.

The overall survival at 5 years of tracheal ACC is approximately $30 \%$ with a reduction to $18 \%$ in cases of extratracheal extension. In cases of intraluminal disease, all the studies shows a 5-year overall survival rate of 50\% [5].

The optimal treatment approach for ACC consists of radical surgical resection with negative margins achievement and reconstruction [2]. Surgical techniques depend on the anatomic region in which the tumor develops. In cases of tumors involving the proximal trachea, concomitant laryngectomy can be required, and a cervical or mediastinal-end tracheostomy is necessary. In cases of a standard resection, an end-to-end anastomosis is usually performed. Even when a radical surgical intervention is theoretically possible, some practical limitations can present [2].

When complete resection cannot be achieved, postoperative radiotherapy seems to have a statistically significant impact on survival [6-8]. ACC of the trachea, in fact, proved to be radiosensitive. Our patient experienced excellent disease control, with a good quality of life, and prolonged overall survival by combining surgery and radiotherapy.

Although there is not an accepted standard, usually the dosage of postoperative radiotherapy is $60 \mathrm{~Gy}$ ( $2 \mathrm{~Gy}$ per fraction, five fractions per week, for a total of 6 weeks). Endotracheal brachytherapy can be used to give a boost on the primary tumor or to treat advanced stages with palliative intent [1].

In cases of inoperable disease, radiotherapy alone can reach a sufficient local control of the disease, but it does not give results comparable to those of surgery. Palliation can be obtained with several procedures, such as electrocoagulation, cryotherapy, photodynamic therapy, or with stents, above all in cases of severe airway obstruction.

Many studies are available in the scientific literature about the employment of radiotherapy in ACC (Table 1). Maziak et al. [6] published a retrospective study in which they analyzed 38 patients affected by ACC of the upper airways and treated by surgery and/or adjuvant radiotherapy. No statistically significant difference between the group of patients treated with adjuvant radiotherapy and the group treated with resection only was found. However, the authors assumed adjuvant radiotherapy to be beneficial for local control and recurrence prevention. This observation is in agreement with the conclusions drawn by Grillo and Mathisen [4].

Kanematsu et al. [7] in a retrospective study reported a long-term survival with 5-year follow-up in patients affected by primary ACC of the lung treated with either adjuvant radiotherapy or palliative radiotherapy in cases of unresectable cancer. After a 5-year follow-up the survival rate of patients treated with surgery and adjuvant radiotherapy was $91 \%$, while in the unresected group the survival rate amounted to $40 \%$.

Le Pechoux et al. [8] proved a survival rate of $65-80 \%$ at 5-year follow-up in patients affected by ACC of the trachea treated with surgery and adjuvant radiotherapy and of $12-27 \%$ in patients with unresectable tumors treated with radiotherapy only.

Regnard et al. [3] conducted a retrospective multicenter study in which 208 patients affected by primary tracheal carcinomas were enrolled. Of these patients, 65 were affected by ACC of the trachea. This study showed a beneficial effect of adjuvant radiotherapy on survival only for patients with incomplete resection of the tumor.

Bonner Millar et al. [9] compared two patients affected by tracheal ACC and treated successfully with definitive radiotherapy: one of them was treated with conventional photons; the other one was treated with a combination of photons and protons. The former had 
Table 1 Studies regarding radiotherapy employment in the treatment of tracheal tumors

\begin{tabular}{|c|c|c|c|c|}
\hline $\begin{array}{l}\text { Author, year of } \\
\text { publication }\end{array}$ & Type of study & Disease & Treatment & Outcome \\
\hline $\begin{array}{l}\text { Maziak et al., } 1996 \\
\text { [6] }\end{array}$ & $\begin{array}{l}\text { Retrospective } \\
\text { study }\end{array}$ & $\begin{array}{l}\text { ACC of the upper } \\
\text { airways }\end{array}$ & $\begin{array}{l}\text { - } 38 \text { patients underwent resection: } 25 \text { received } \\
\text { adjuvant radiotherapy (various dosages); } 7 \text { did } \\
\text { not receive adjuvant therapy } \\
-6 \text { inoperable patients treated with primary } \\
\text { radiotherapy (50 to } 75 \text { Gy) }\end{array}$ & $\begin{array}{l}\text { - Mean survival with adjuvant radiotherapy: } \\
88 \pm 76 \text { months } \\
\text { - Mean survival with resection only: } 131 \pm \\
131 \text { months } \\
\text { - Mean survival with primary radiotherapy } \\
\text { alone: } 74 \pm 64 \text { months }\end{array}$ \\
\hline $\begin{array}{l}\text { Kanematsu et al., } \\
2002[7]\end{array}$ & $\begin{array}{l}\text { Retrospective } \\
\text { study }\end{array}$ & $\begin{array}{l}\text { Primary ACC of } \\
\text { the lung }\end{array}$ & $\begin{array}{l}\text { - } 5 \text { of } 6 \text { patients underwent resection and } \\
\text { received adjuvant RT ( } 50-61.2 \mathrm{~Gy} \text { ) } \\
-5 \text { patients with unresectable tumor underwent } \\
\text { primary RT ( } 50 \text { to } 70 \text { Gy) }\end{array}$ & $\begin{array}{l}\text { At a } 5 \text {-year follow-up: } \\
\text { - survival rate in patients treated with } \\
\text { adjuvant RT: } 91 \% \\
\text { - survival rate in patients treated with } \\
\text { primary RT: } 40 \%\end{array}$ \\
\hline $\begin{array}{l}\text { Regnard et al., } 1996 \\
\text { [3] }\end{array}$ & $\begin{array}{l}\text { Multicenter } \\
\text { retrospective } \\
\text { study }\end{array}$ & $\begin{array}{l}\text { Primary tracheal } \\
\text { tumors, including } \\
\text { ACC }\end{array}$ & $\begin{array}{l}26 \text { of } 60 \text { patients underwent resection and } \\
\text { received adjuvant therapy }\end{array}$ & $\begin{array}{l}\text { Radiotherapy showed beneficial effects on } \\
\text { survival in cases of incomplete resection } \\
\text { only }\end{array}$ \\
\hline $\begin{array}{l}\text { Grillo and Mathisen, } \\
1990[4]\end{array}$ & $\begin{array}{l}\text { Series of } \\
\text { cases }\end{array}$ & $\begin{array}{l}\text { Primary tracheal } \\
\text { tumors, including } \\
\text { ACC }\end{array}$ & $\begin{array}{l}60 \text { of } 80 \text { patients affected by ACC underwent } \\
\text { surgical resection, and nearly all of them } \\
\text { received postoperative RT; } 12 \text { patients treated } \\
\text { with RT only ( } 9 \text { of which died of carcinoma) }\end{array}$ & $\begin{array}{l}\text { Resection associated to RT gives } 2 \text { to } 4 \\
\text { years survival }\end{array}$ \\
\hline
\end{tabular}

ACC adenoid cystic carcinoma, $R T$ radiotherapy

no evidence of disease at a 5-year follow-up; the latter had no evidence of disease at 11 months of follow-up.

Bittner et al. [10] published a retrospective study in which 20 patients affected by ACC of the trachea were treated with fast neutron radiotherapy, six of these patients received boost by endobronchial brachytherapy. At a 46-month follow-up, no statistically significant difference in overall survival and of locoregional control rate was found between the two groups.

Radiotherapy should always be performed in order to cover the entire tumor bed and to spare the surrounding normal tissues. In cases of treatment of tracheal tumors, preventing near structures (such as esophagus, lungs, and spinal cord) from accidental irradiation is particularly important to limit side effects and late complications. Alongi et al. [1] in a case report described the employment of helical tomotherapy as adjuvant treatment for a patient affected by tracheal ACC. Helical tomotherapy is a technique that performs IMRT with a helical delivery pattern. This technique allows a more precise irradiation of the tumor bed, minimizing accidental irradiation of normal structures. There is no evidence about the usefulness of chemotherapy in the treatment of tracheal ACC.

\section{Conclusions}

In conclusion, due to the rarity of the disease and thus the lack of randomized clinical trials, there is not yet a standardized therapeutic approach to tracheal ACC. In our experience, considering the slow tumor growth and despite our patient's short follow-up, the combinatorial strategy of a debulking surgery followed by postoperative radiotherapy successfully achieved adequate disease control, suggesting it would be considered in the treatment option of locally advanced ACC of the trachea.
Acknowledgements

Not applicable.

\section{Funding}

No funding was received.

\section{Availability of data and materials}

Data sharing is not applicable to this article, because no datasets were generated or analyzed.

\section{Authors' contributions}

GPS, EM, and AAP reviewed the literature and prepared the manuscript. ADM prepared Fig. 2 and the manuscript. CDC prepared Fig. 1 and the manuscript. GLR and ST reviewed the literature. All authors read and approved the final manuscript.

\section{Ethics approval and consent to participate}

The authors declare that ethics approval was not required for this case report.

\section{Consent for publication}

Written informed consent was obtained from the patient for publication of this case and accompanying images. A copy of the written consent is available for review by the Editor-in-Chief of this journal.

\section{Competing interests}

The authors declare that they have no competing interests.

\section{Publisher's Note}

Springer Nature remains neutral with regard to jurisdictional claims in published maps and institutional affiliations.

\section{Author details}

"UOC of Oncology - ASL Latina - Distretto 1, University of Rome "Sapienza", Aprilia, LT, Italy. ${ }^{2}$ Department of Hematology/Oncology and Stem Cell Transplantation, Bambino Gesù Children's Hospital, IRCCS, Rome, Italy. ${ }^{3}$ Radiotherapy Unit, Santa Maria Goretti Hospital, ASL, Latina, Italy. ${ }^{4} \mathrm{UOC}$ of Pathology, Department of Medical-Surgical Sciences and Bio-Technologies, University of Rome "Sapienza", Polo Pontino, I.C.O.T., Latina, Italy. 
Received: 17 June 2018 Accepted: 24 January 2019

Published online: 06 March 2019

\section{References}

1. Alongi F, et al. Adenoid cystic carcinoma of trachea treated with adjuvant hypofractionated tomotherapy. Case report and literature review. Tumori. 2008;94:121-5.

2. Honings J, et al. Clinical aspects and treatment of primary trachea malignancies. Acta Otolaryngol. 2010;130:763-72.

3. Regnard J, et al. Results and prognostic factors in resections of primary tracheal tumors: a multicenter retrospective study. J Thorac Cardiovasc Surg. 1996;111:808-14.

4. Grillo HC, Mathisen DJ. Primary tracheal tumors: treatment and results. Ann Thorac Surg. 1990;49:69-77.

5. Moran CA, et al. Primary salivary gland type tumours of lung. Semin Diagn Pathol. 1995;12:106-22.

6. Maziak DE, et al. Adenoid cystic carcinoma of the airway: thirty-two year experience. J Thorac Cardiovasc Surg. 1996;112:1522-32.

7. Kanematsu T, et al. Treatment outcome of resected and nonresected primary adenoid cystic carcinoma of the lung. Ann Thorac Cardiovasc Surg. 2002;8(2):74-7.

8. Le Pechoux $C$, et al. Thoracic adenoid cystic carcinomas. Cancer Radiother. 2005;9(6-7):358-61.

9. Bonner Millar LP, et al. Definitive radiotherapy for unresected adenoid cystic carcinoma of the trachea. Chest. 2012;141:1323-6.

10. Bittner N, et al. Treatment of Locally Advanced Adenoid Cystic Carcinoma of the Trachea with Neutron Radiotherapy. Int J Radiat Oncol Biol Phys. 2008; 72:410-4.

Ready to submit your research? Choose BMC and benefit from:

- fast, convenient online submission

- thorough peer review by experienced researchers in your field

- rapid publication on acceptance

- support for research data, including large and complex data types

- gold Open Access which fosters wider collaboration and increased citations

- maximum visibility for your research: over $100 \mathrm{M}$ website views per year

At BMC, research is always in progress.

Learn more biomedcentral.com/submissions 